\title{
Pelatihan Keterampilan Membuat Kerajinan Bagi Para Anggota PJJI “Armalah”
}

\author{
Toyibah Kusumawati ${ }^{1}$, Listya Asyfa \\ Muhaymina ${ }^{2}$ \\ Program Studi Kriya Seni, Fakultas Seni Rupa \\ Institut Seni Indonesia Yogyakarta \\ Jalan Parangtritis Km 6,5, Sewon, Bantul, Daerah Istimewa Yogyakarta 55188 \\ No. Hp.: ${ }^{1}+6285100413445,{ }^{2}+6285336183352$ \\ E-mail: 'toyibahkusumawati@yahoo.com, ${ }^{2}$ listyamuhaymina@gmail.com
}




\title{
Pelatihan Keterampilan Membuat Kerajinan Bagi Para Anggota PJJI “Armalah”
}

\author{
Toyibah Kusumawati ${ }^{1}$, Listya Asyfa Muhaymina ${ }^{2}$ \\ Program Studi Kriya Seni, Fakultas Seni Rupa \\ Institut Seni Indonesia Yogyakarta \\ Jalan Parangtritis Km 6,5, Sewon, Bantul, Daerah Istimewa Yogyakarta 55188 \\ No. Hp.: ${ }^{1}+6285100413445,{ }^{2}+6285336183352$ \\ E-mail: ${ }^{1}$ toyibahkusumawati@yahoo.com. ${ }_{2}$ listyamuhaymina@gmail.com
}

\begin{abstract}
Abstrak
Persatuan Janda-Janda Indonesia “Armalah” terdiri atas anggota dengan ekonomi menengah ke bawah, yang sebenarnya sangat memerlukan penghasilan yang bisa memenuhi kebutuhan hidupnya. Oleh karena itu, kegiatan pengabdian ini memberikan pelatihan sulam pita dengan pertimbangan bahwa nantinya mereka dapat menjadikan keterampilan ini sebagai pilihan untuk dikembangkan dalam kehidupannya, sebagai mata pencaharian. Metode pelatihan ini adalah ceramah dan praktik. Hasil kegiatan penyuluhan yang telah dilaksanakan ada beberapa hal yang telah dicapai, di antaranya adalah (1) peserta memahami dan menguasai semua materi yang diberikan dalam pelatihan; (2) pengetahuan, keterampilan, dan daya kreativitas peserta bertambah; dan (3) peserta mampu membuat beberapa macam produk kerajinan sulam pita dan lain-lain.
\end{abstract}

Kata kunci: sulam pita, PJJI “Armalah”, keterampilan

\section{Skill Training to Create Crafts for PJJI “Armalah” Group Members}

\section{Abstract}

"Armalah" Indonesian Widowers community group consists of people of low-end financial state who are in dire need of extra income to cover their daily necessities. Thus, this community service is aimed to give a training of ribbon embroidery with consideration that this skill can be useful as an option to be developed further in their lives as part of profession. The training methods conducted are lectures and practices. The result of the training shows that there are several things successfully transferred: (1) participants are able to understand and master all the lesson given in the training; (2) the increase of participants' knowledge, skill, and creativity; (3) participants are able to create a range of ribbon embroidery craft products.

Keyword: ribbon embroidery, PJJI “Armalah”, skill 


\section{PENDAHULUAN}

Persaudaraan Janda-Janda Indonesia (PJJI) Armalah merupakan lembaga sosial yang berdiri dan berkembang di bawah naungan Yayasan Armalah. Anggotanya terdiri atas para janda dari berbagai daerah, antara lain dari Sleman, Bantul, Yogyakarta, Gunungkidul, Kulonprogo, dan Malang. Pada saat ini tercatat anggotanya berjumlah 871 orang. PJJI “Armalah" telah berbadan hukum dari Kemenkumham SK Nomor AHU 0009295 AHA 01.07 Tahun 2017. Berkantor pusat di Jalan Selokan Mataram No. 3, Babarsari, Depok, Sleman, Yogyakarta. Adanya PJJI “Armalah" di Yogyakarta ini menjadi angin segar bagi para janda. Lembaga ini berusaha untuk mewadahi para janda agar tetap dapat dihormati, mandiri, dan bermartabat. Hal ini mengingat bahwa pada umumnya seorang janda baik karena dicerai ataupun ditinggal mati oleh suaminya merupakan salah satu golongan yang memiliki kerentanan, baik itu pada aspek ekonomi maupun psikis.

Permasalahan umum dari PJJI "Armalah" adalah sebagian anggotanya dari ekonomi menengah ke bawah, yang sebenarnya sangat memerlukan penghasilan yang bisa memenuhi kebutuhan hidupnya. Sebagian dari mereka belum mempunyai pekerjaan tetap. Kegiatan PJJI “Armalah”, di antaranya seperti yang tersebut di atas, telah dapat dilakukan dengan melibatkan anggota sebagai peserta dalam kegiatan tersebut. Para anggota dapat menindaklanjuti dengan memproduksi sabun dan hasilnya dijual di toko PJJI “Armalah”. Namun, penjualan dari produk sabun ini masih belum lancar. Permasalahan lain adalah bahwa para anggota yang tergabung dalam lembaga tersebut selama ini belum pernah mengadakan/mengikuti kegiatan yang berhubungan dengan bidang keterampilan membuat kerajinan. Padahal keterampilan ini cukup penting diberikan kepada para angota karena nantinya mereka dapat memanfaatkan dan menjadikan keterampilan ini sebagai pilihan untuk dikembangkan dalam kehidupannya, sebagai pekerjaan yang dapat mendatangkan penghasilan.

Menanggapi permasalahan seperti tersebut di atas, penyuluh tertarik untuk membantu para anggota dari PJJI Armalah, dengan cara memberikan pelatihan di bidang keterampilan. Pelatihan ini diberikan dengan pertimbangan bahwa nantinya mereka dapat menjadikan keterampilan ini sebagai pilihan untuk dikembangkan dalam kehidupannya, sebagai mata pencaharian. Pelatihan yang akan dilaksanakan adalah pelatihan keterampilan membuat aksesoris/cenderamata dari manikmanik, kain perca, kain organdi, dan lain-lain; membuat kerajinan sulam pita, dan lain-lain.

Kegiatan penyuluhan dilaksanakan di kantor pusat PJJI “Armalah”, Jalan Selokan Mataram Nomor 3, Babarsari, Caturtunggal, Depok, Sleman, Yogyakarta. Tujuan yang ingin dicapai dalam kegiatan penyuluhan seni ini adalah (1) memberikan pengetahuan dan keterampilan membuat kerajinan dengan berbagai macam bahan dan teknik kepada para anggota PJJI "Armalah"; (2) membekali para anggota di bidang keterampilan membuat kerajinan, dengan harapan kelak dapat dimanfaatkan untuk dikembangkan dalam kehidupannya, sebagai pekerjaan yang dapat mendatangkan penghasilan; (3) menyiapkan sumber daya manusia yang terampil dan kreatif dalam bidang keterampilan membuat kerajinan; dan (4) membantu menyukseskan program dari PJJI “Armalah”, dalam rangka untuk mewujudkan visi dan misinya.

\section{METODE PENGABDIAN}

Metode yang digunakan dalam kegiatan penyuluhan ini adalah ceramah dan praktik. Metode ceramah digunakan untuk menyampaikan materi teori. Teori yang disampaikan terkait kerajinan sulam pita, yaitu wawasan tentang kerajinan sulam pita, 
pengetahuan bahan dan alat yang digunakan dalam proses pembuatan kerajinan sulam pita, dan pengetahuan tentang teknik pembuatan kerajinan sulam pita. Selain itu, wawasan tentang aksesoris atau cenderamata, pengetahuan bahan dan alat yang digunakan, serta teknik pembuatannya. Metode praktik digunakan untuk membuat produk kerajinan sulam pita, di antaranya meliputi jilbab, bros, dan tas. Selain itu, metode praktik digunakan untuk membuat aksesoris/cenderamata dari manik-manik, kain perca, kain organdi, dan lain lain.

\section{HASIL DAN PEMBAHASAN}

Pelatihan ini akan diikuti oleh 20 peserta, yaitu anggota dari PJJI “Armalah" di Babarsari, Caturtunggal, Depok, Sleman, Yogyakarta. Pelatihan ini disesuaikan dengan visi dan misi PJJI “Armalah”. Visi PJJI “Armalah” adalah membentuk kemandirian para janda di bidang agama, ekonomi, sosial, dan kemasyarakatan sehingga menjadi pribadi yang mandiri, terhormat, bermartabat, dan sejahtera. Misi PJJI “Armalah” adalah berjuang keras untuk mewujudkan dan memberikan layanan sosial yang bermanfaat dan membantu para anggota, empowering (pemberdayaan) perempuan agar para anggota mampu mandiri secara ekonomi dan menjadi pribadi yang tangguh sehingga mampu menyelesaikan persoalan yang dihadapi. Motto PJJI “Armalah” adalah mandiri, terhormat, bermartabat, dan sejahtera.
Pelatihan ini terlaksana sejumlah tiga kali. Adapun materi yang disampaikan adalah pengenalan kerajinan sulam pita dan aksesoris/cenderamata, dilanjutkan praktik menghias kerudung dengan sulam pita teknik 1. Sulam pita merupakan salah satu seni menyulam yang mempergunakan pita sebagai bahan sulamnya. Sulam pita adalah salah satu teknik menghias kain dengan cara menjahitkan pita secara dekoratif ke atas benda yang akan dihias sehingga terbentuk suatu desain hiasan baru dengan menggunakan berbagai macam tusuk-tusuk hias (Puspitowati, 2008). Sulam pita adalah sulaman yang menggunakan pita berbagai ukuran dan bahan untuk membuat motif-motif bunga (Amelia, 2006). Sulam pita atau ribbon embroidery sudah dikenal sejak pertengahan abad 17. Pada saat itu sulaman pita tidak hanya digunakan untuk menghias busana, tetapi juga untuk menghias tas tangan, kerudung, selendang, payung, dan berbagai peralatan rumah tangga. Dalam pelatihan ini sulam pita diterapkan untuk menghias kerudung. Metode ceramah dilaksanakan untuk memberi pengantar dalam setiap materi yang akan disampaikan dan pengetahuan tentang kerajinan sulam pita. Metode ceramah juga dapat digunakan untuk merefleksi setiap pertemuan atau setiap materi pelatihan (Heldisari, 2019). Gambar 1 merupakan dokumentasi pelaksanaan praktik sulam pita. 


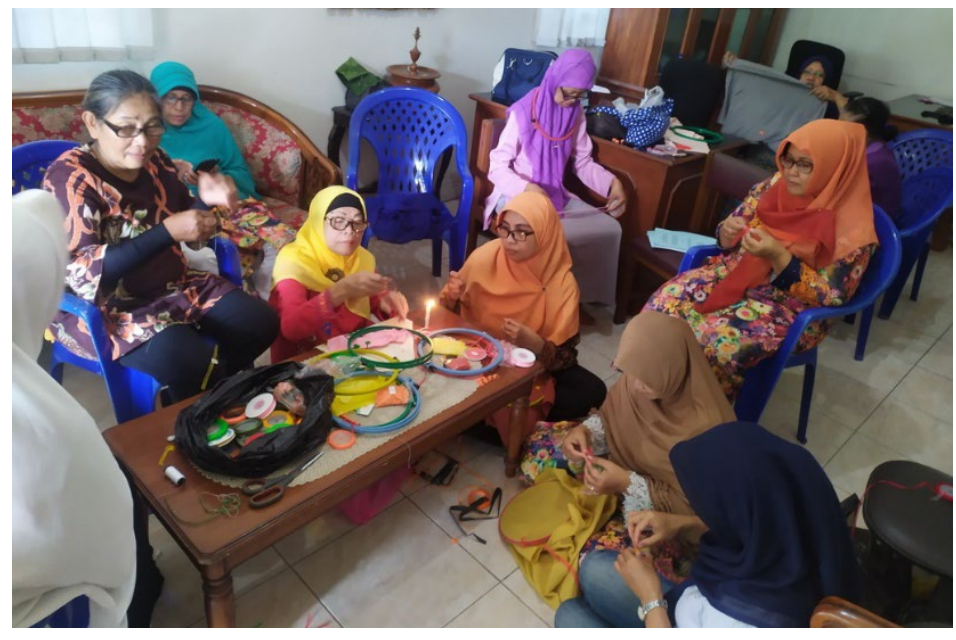

Gambar 1 Pelaksanaan praktik sulam pita

Hasil kegiatan penyuluhan yang telah dilaksanakan ada beberapa hal yang telah dicapai, di antaranya adalah (1) peserta memahami dan menguasai semua materi yang diberikan dalam pelatihan; (2) pengetahuan, keterampilan, dan daya kreativitas peserta bertambah; (3) peserta mampu membuat beberapa macam produk kerajinan sulam pita dan lain-lain. Gambar 2 adalah hasil pelatihan menghias kerudung dengan sulam pita teknik 1 .

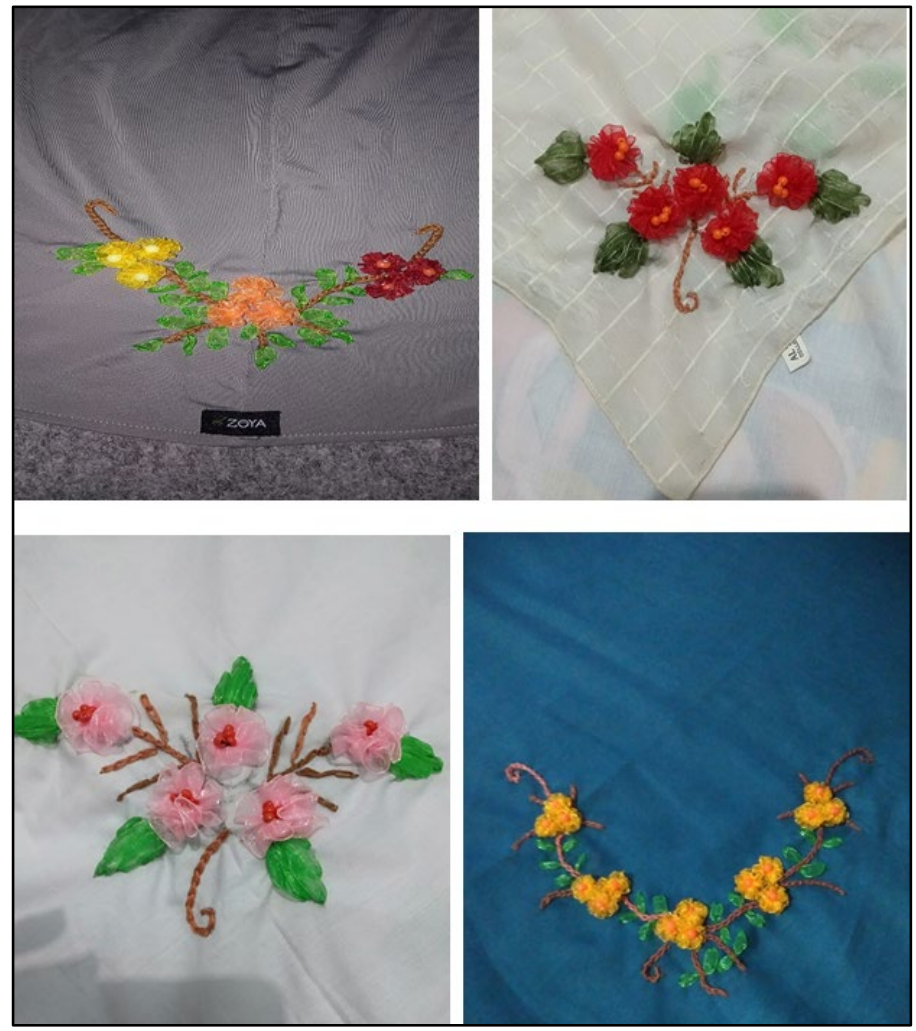

Gambar 2 Hasil Pelatihan Sulam Pita 
Manfaat dari program pelatihan ini bagi dosen mendapatkan pengalaman dalam mentransfer ilmu pengetahuan dan keterampilan kepada para anggota PJJI "Armalah". Bagi PJJI "Armalah" dapat membantu mewujudkan visi dan misi PJJI “Armalah". Bagi pemerintah daerah adalah membantu program pemberdayaan masyarakat.

\section{SIMPULAN}

Program penyuluhan seni bagi para anggota PJJI “Armalah" di Babarsari, Caturtunggal, Depok, Sleman, Yogyakarta belum berhasil dilaksanakan dengan baik atau belum selesai pelaksanaannya. Materi pelatihan yang telah direncanakan dalam penyuluhan ini adalah kerajinan sulam pita dan aksesoris/cenderamata sebagian telah dapat disampaikan dengan baik. Namun, praktik tentang aksesoris belum dapat terselesaikan karena pandemi Covid-19. Akan tetapi, dalam menghias sulam pita sudah dipahami dengan baik dan semoga dapat menjadi bekal keterampilan dalam berwirausaha.

\section{SARAN}

Saran agar hasil pengabdian
selanjutnya jauh lebih baik adalah
pengadaan alat peraga sebaiknya jumlahnya
ditambah. Dengan demikian, dapat
memenuhi kebutuhan kegiatan penyuluhan
sehingga hasilnya maksimal.

\section{UCAPAN TERIMA KASIH}

Penulis mengucapkan terima kasih kepada Lembaga Penelitian dan Pengabdian Masyarakat ISI Yogyakarta yang telah memberi dukungan terhadap keberhasilan pengabdian ini.

\section{DAFTAR PUSTAKA}

Amelia, R. (2008). Teknik Dasar Sulam Pita. Jakarta: PT Rineka.

Heldisari, H. P. (2019). Pembelajaran Teknik Rekam di Sekolah Menengah Kejuruan (Seni Musik) Melalui Model Pembelajaran Personal". Faktor Jurnal Ilmiah Kependidikan.

Puspitowati, W. (2008). Teknik Dasar Sulam Pita, Payet, dan Benang. Jakarta: Kawan Pustaka. 
$\bar{A}$

Agung Sutrisno $\cdot 2,3,4$

Anon Suneko · 2, 3, 4

atraksi wisata $\cdot 144,145,146,147,148,150,151$,

$152,153,154,155$

autis $\cdot 16,17,18,21,26,27,105$

\section{B}

batik $\cdot 36,82,83,84,85,86,89,112,114,115,116$, $117,120,121,122,123,124,126,127$

batik tulis $\cdot 82,83,84,85,89,116,123,127$

Budi Hartono $\cdot 88,89$

Budi Raharja $\cdot 17,143,144$

\section{D}

dalang $\cdot 63,64,65,67$

Desa Ngluwar · 119, 120, 121, 122, 123, 124, 125,

126,127

Dindin Heryadi · 111, 112

Djandjang Purwo Sedjati · 119, 120, 125, 126

Dusun Tlogosari $\cdot 42,43$

$\bar{E}$

etika menabuh $\cdot 159,166$

$F$

Fajar Apriyanto $\cdot 128,129,138$

Fotografi $\cdot 88,89,91,95,99,128,129,131,132$,

$134,135,141$

G

gamelan $\cdot 4,7,10,13,14,17,18,19,20,21,22,26$, $27,34,63,64,65,97,104,106,107,113,114$, $159,160,161$

gangsaran $\cdot 19,21,160$

Gejog Lesung $\cdot 2,70,71,72,75$

Gending $\cdot 10,65,163,164,165$

Gojeg Lesung · 2, 70, 71, 72, 73, 74, 75, 76, 77, 78

Gondang Sari $\cdot 2$, 51, 52, 53, 54, 55, 57, 58, 59 $\operatorname{grup} \cdot 159,161,167,168$

Gunungkidul · 2, 29, 30, 31, 32, 33, 128, 129, 130,

131,171

guru $\cdot 5,17,18,19,20,21,22,26,27,105,162$

H

Hendro Martono $\cdot 2,29$

$\bar{I}$

I Made Sukanadi · 2, 41, 42, 45, 46, 47, 48

Indah Nuraini $\cdot 2,51,52$

Ismael Setiawan $\cdot 111,112$

$\bar{J}$

Junaidi $\cdot 1,2,62,65,66,67,68$

\section{K}

kaderisasi $\cdot$ 4, 5, 6, 72

Kampoeng Wisata Titik Nol Jateng · 143, 144, 145, 146, 147, 148, 150, 151, 152, 153, 154, 155

karawitan · 4, 5, 6, 7, 8, 10, 11, 26, 31, 64, 67, 89, $90,92,93,97,112,113,114,117,159,160,161$ $162,166,167$

Kelurahan Terban $\cdot 159,160,161,167$

kerajinan bambu $\cdot 42,43,48$

ketawang $\cdot 160$

keterampilan $\cdot 6,10,17,18,20,21,82,83,84,85$, $86,89,91,92,97,105,118,120,122,123,129$, $131,139,140,150,170,171,173,174$

КОМРАK · 128, 129, 130, 131, 132, 133, 136, 137, $139,140,141$

kriya $\cdot 81,82,85,89,92,97$

$\bar{L}$

ladrang $\cdot 160,161$

lancaran $\cdot 19,21,94,160,161$

Listya Asyfa Muhaymina $\cdot 169,170$

LPM ISI Yogyakarta · 40, 52, 53, 59, 100, 104, 110, $141,148,150,154,159,168$ 
$\bar{M}$

Mahdi Naufal Hilmi $\cdot 143,144$

$N$

Nawung Sekar $\cdot 30,34,35,36,37$

Nurul Amalina $\cdot 103,104$

$\bar{P}$

Pantai Pulang Sawal · 128, 129, 130, 131, 132, 133, $134,138,140,141$

pariwisata $\cdot 39,52,54,113,121,122,129$

pelatihan $\cdot 4,5,6,11,18,20,26,27,30,31,32,33$,

$34,37,43,44,45,48,64,68,74,75,78,82,83$,

$85,86,89,90,91,92,93,94,97,100,105,108$,

$114,115,121,122,123,124,126,127,132,141$,

$145,146,148,152,154,161,162,166,170,171$,

$172,173,174$

pemberdayaan $\cdot 7,13,89,114,120,123,127,144$,

$147,149,150,151,172,174$

pembinaan · 5, 42, 44, 48, 52, 53, 55, 59, 72, 89, 91, $92,93,97,104,114,122,144,146,147,148$,

$149,150,151,152,153,155$

pembinaan seni $\cdot 42,52,89,144,146,147,148,149$ $150,151,152,153,155$

pemotretan $\cdot 129,131,133,134,135,136,137,138$, 139,140

penyuluhan seni $\cdot 4,6,9,11,13,14,17,27,31,40$, $44,48,49,52,59,64,71,73,74,77,78,82,83$, $84,85,86,89,120,123,124,126,129,140,141$, 171,174

pewarnaan celup $\cdot 82,83,84,89$

pewisata $\cdot 146,147,154,155$

PJJI $\cdot 169,170,171,172,174$

$\mathrm{PkM} \cdot 129,131,132,133,140,141$

playon $\cdot 161$

produk interior $\cdot 82$

Purwanto Lephen $\cdot 143,144$

$\boldsymbol{R}$

Rambeanak $\cdot 111,112,113,114,115,116,117,118$

Rano Sumarno $\cdot 2,70,71$

Reog Kaloka · 2, 29, 30, 31, 32, 34, 35, 38, 39, 40 ricikan $\cdot 161$

S

Sekolah Khusus Autis Bina Anggita Yogyakarta · 2, 16, $17,18,21,27$

Sekolah Luar Biasa $\cdot 18,19,104,105,109,110$

seni batik $\cdot 82,84,85,86,89$

seni karawitan · 5, 6, 7, 11, 14, 92, 159, 160

seni musik $\cdot 73,105,144,146$

seni pertunjukan $\cdot 11,32,54,55,71,72,94,112,121$

seni rupa $\cdot 95,112$

seni suara $\cdot 144,146,147,148,149,151,152,154$

seni wayang $\cdot 63,64,67$

sulam pita $\cdot 170,171,172,173,174$

Sutrisni $\cdot 158,159$

$\bar{T}$

tari Gunungan · 52, 54

tari Jawa $30,34,38,39$

teknik menabuh $\cdot 114,159,161$

teori fotografi $\cdot 129,134$

Toyibah Kusumawati $\cdot 169,170$

$\bar{U}$

unggah-ungguh $\cdot 159,161,162,166$

$\bar{V}$

videografi $\cdot 89,90,91,92,93,94,96,97$

vokal gerongan $\cdot 161$

vokal sindenan $\cdot 161$

$W$

wayang multilevel $\cdot 63,64,65,66,67$

$\bar{Y}$

Yuni Estikasari $\cdot 119,120$ 


\section{UCAPAN TERIMA KASIH}

Ucapan terima kasih disampaikan kepada para mitra bebestari:

1. Dr. Stepanus Hanggar Budi Prasetiya, S.Sn., M.Si. (ISI Yogyakarta)

2. Dr. Junaidi., S.Kar., M.Hum. (ISI Yogyakarta)

3. Dr. Ahmad Nizam, M.Sn. (ISI Yogyakarta)

4. Asep Saepudin, S.Sn., M.A. (ISI Yogyakarta)

5. Dr. Wadiyo, M.Si. (FBS, Universitas Negeri Semarang)

6. Dr. M. Ibnan Syarif, S. Pd., M. Sn. (FBS, Universitas Negeri Semarang)

7. Indar Sabri, S.Sn., M.Pd. (FBS, Universitas Negeri Surabaya)

8. Dr. Edi Kurniadi, M.Pd. (FKIP, Universitas Sebelas Maret)

9. Dr. Sahrul N., S.S., M.Si. (Prodi Seni Teater, FSP, ISI Padang Panjang)

10. Dr. Agus Cahyono M.Hum. (Prodi Pendidikan Seni Pascasarjana Universitas Negeri Semarang)

yang telah membantu menilai, menyeleksi, dan memberi masukan demi penyempurnaan artikel-artikel yang dimuat dalam JURNAL PENGABDIAN SENI Volume 2 Nomor 1 (Mei 2021 dan Volume 2 Nomor 2 (November 2021). 
